\title{
Nucleophilic Reactions of Imines
}

\author{
Viqar Uddin Ahmad, Anwer Basha, and Atta-ur-Rahman \\ Postgraduate Institute of Chemistry, University of Karachi, Karachi-32, Pakistan
}

(Z. Naturforsch. 30 b, 128-131 [1975]; received September 13, 1974)

Imines, Enamines, Alkylation, Tautomerism

\begin{abstract}
The reaction of imines with various electrophiles have afforded only $\mathrm{N}$-alkylated products, contrary to earlier reports.
\end{abstract}

While a large amount of work has been done on the synthetic applications of tertiary enamines, pioneered by STORK and coworkers ${ }^{1,2}$, less is known about the scope of similar applicability of secondary enamines. Secondary enamines predominantly exist in the imino form both in aliphatic and in cyclic compounds except in cases where the

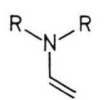

tertiary

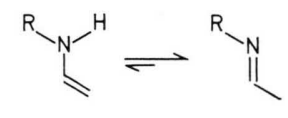

secondary

imine

enamine form may be stabilized by conjugation ${ }^{3}$. The possibility of tautomeric equilibrium in ketimines between the imine and enamine forms was first suggested by RoBrnson in $1919^{4}$ in harmaline but later Abramovitch and SpenseR ${ }^{5}$ argued that this need not be invoked ${ }^{5}$. Conclusive proof for the existence of such an equilibrium was subsequently obtained in these laboratories by NMR experiments involving deutration of harmaline ${ }^{6}$ and its reactions with various electrophiles to afford both C- and $\mathrm{N}$-alkylated products ${ }^{7,8}$.

The present study was undertaken on account of a report from PFAU and RIBIERE ${ }^{9,10}$ that only C-alkylated products were obtained when isopropylidene isopropylamine and cyclohexylidene cyclohexylamine were allowed to react with dimethyl maleate. The authors claimed these to be the first demonstrations of C-alkylations of ketimines via their enamine tautomers. A survey of the literature however showed that two groups of workers had earlier demonstrated similar reactivity in 3,4-dihydroisoquinoline and tetrahydropyridine systems

Requests for reprints should be sent to Dr. Atta-ur-Rahman, Postgraduate Institute of Chemistry, University of Karachi, Karachi-32, Pakistan. in their reactions with acrylamide and unsaturated esters ${ }^{11,12}$.

The two imines chosen for study were $\mathrm{N}$-isopropylidene cyclohexylamine and $\mathrm{N}$-ethylidenecyclohexylamine so as to investigate the reactivity of both ketimine and aldimine systems with various electrophiles. The two imines were prepared according to the methods described by CAMPBELL ${ }^{13}$ and NoRToN ${ }^{14}$, respectively.

N-Isopropylidene cyclohexylamine was refluxed with an equimolar quantity of methyl acrylate in dry benzene for 14.5 hours. The mixture on distillation and column chromatography afforded a pure substance which was crystallized as the oxalate m.p. $134-135{ }^{\circ} \mathrm{C}(55 \%$ yield $)$ which analysed for $\mathrm{C}_{22} \mathrm{H}_{42} \mathrm{~N}_{2} \mathrm{O}_{9}$. The mass spectrum exhibited a molecular ion at $m / e=185$ and the infrared spectrum showed ester absorption at $1730 \mathrm{~cm}^{-1}$ but no $\mathrm{C}=\mathrm{N}$ stretching vibrations were present. The NMR spectrum (in $\mathrm{d}_{6} \mathrm{DMSO}$ ) showed a threeproton singlet at $\delta 3.67$ and a triplet of the methylene protons geminal to the ester group at $\delta 2.79$ $(J=6 \mathrm{c} / \mathrm{s})$. Another two proton triplet was centred at $\delta 2.53(J=6 \mathrm{c} / \mathrm{s})$ of the methylene adjacent to the nitrogen. A one-proton multiplet of the methine proton adjacent to the nitrogen was located at $\delta$ 2.53. The above evidence clearly showed that $\mathrm{N}$-alkylation of the ketimine had occurred followed by hydrolysis of the resulting enamine (2) during work-up to afford the secondary amine (3).

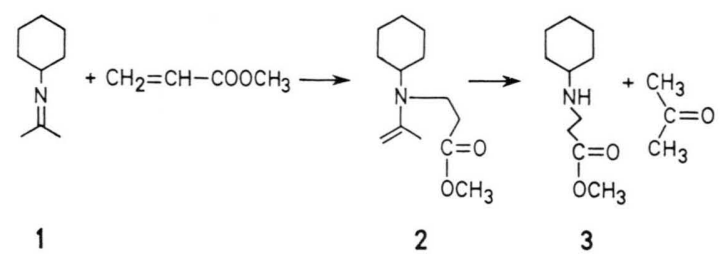


Similarly the ketimine was refluxed with acrylonitrile in benzene for 10 hours and the major product separated by column chromatography. The oil obtained was crystallised as the oxalate, m.p. $200-203{ }^{\circ} \mathrm{C}(50 \%$ yield $)$ analysis of which indicated the molecular formula of the base $\mathrm{C}_{9} \mathrm{H}_{16} \mathrm{~N}_{2}$ and afforded the parent peak at $m / e=152$. The IR spectrum showed a peak at $2240 \mathrm{~cm}^{-1}$ due to the cyano group. The NMR spectrum (in $\mathrm{d}_{6} \mathrm{DMSO}$ ) exhibited a two-proton triplet at $\delta 3.27(J=6 \mathrm{c} / \mathrm{s})$ and a two proton triplet at $\delta 2.98(J=6 \mathrm{cps})$ of the two methylenes adjacent to the cyano group and geminal to the nitrogen respectively. A oneproton multiplet of the methine proton adjacent to the nitrogen was present at $\delta 2.5$. The above data indicate that $\mathrm{N}$-alkylation had taken place followed by hydrolysis giving rise to the secondary amine (4).

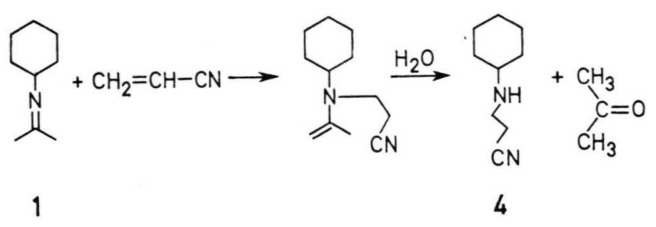

When the ketimine and allylbromide were refluxed in dry dioxan for 5 hours, one major faster moving spot was indicated on t.l.c. Extraction from ether after basification, yielded a liquid which was crystallised as the oxalate m.p. $189-194{ }^{\circ} \mathrm{C}$ $\left(55 \%\right.$ yield) which analysed for $\mathrm{C}_{9} \mathrm{H}_{17} \mathrm{~N}(\mathrm{COOH})_{2}$. The mass spectrum showed the molecular ion at $139 \mathrm{~m} . \mathrm{u}$. and the IR spectrum exhibited a peak at $1630 \mathrm{~cm}^{-1}$ due to $\mathrm{C}=\mathrm{C}$ bond. The NMR spectrum (in $\mathrm{d}_{6}$ DMSO) showed a multiplet of one olefinic proton at $\delta 5.98$ and a two-proton multiplet of the unsaturated methylene at $\delta 5.4$. There was a twoproton doublet at $\delta 3.6(J=6 \mathrm{cps})$ due to the methylene proton geminal to the nitrogen. The protons of the cyclohexyl group resonated in the region of $\delta$ 1.1-2.5. This indicated that again $\mathrm{N}$ alkylation had taken place followed by hydrolysis resulting in the formation of the secondary amine (5).

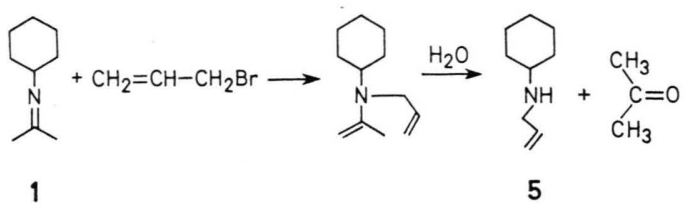

Benzoyl chloride reacted with the cold ketimine instantaneously and the precipitate thus obtained was taken up in water, basified with ammonia and extracted with ethyl acetate. The organic extracts on evaporation afforded crystals, m.p. $148-152{ }^{\circ} \mathrm{C}$ $\left(80 \%\right.$ yield) which analysed for $\mathrm{C}_{13} \mathrm{H}_{17} \mathrm{NO}$. Its mass spectrum showed the molecular ion at $203 \mathrm{~m}$.u. and the NMR spectrum (in $\mathrm{d}_{6}$ DMSO) showed a five-proton multiplet of the benzene ring at $\delta$ 7.58.0 and a multiplet of eleven protons of the cyclohexyl moiety was observable in the region between $\delta$ 1.2-3.5. The above physical data indicate that $\mathrm{N}$-acylation was followed by hydrolysis to afford the amide (6).

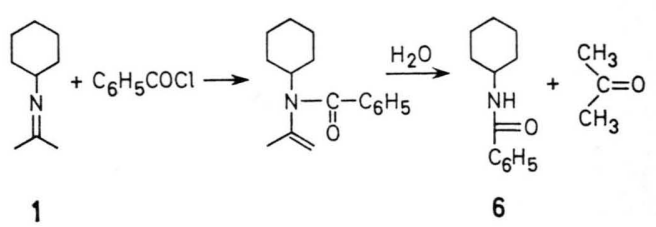

Equimolar quantities of the ketimine and benzyl chloride were refluxed in dry dioxan for 8 hours. The product on basification readily afforded the oxalate in a crystalline form, m.p. $216-219{ }^{\circ} \mathrm{C}$ $(50 \%$ yield $)$. The microanalysis of the salt showed the molecular formula of the base to be $\mathrm{C}_{13} \mathrm{H}_{19} \mathrm{~N}$ and the mass spectrum exhibited the molecular ion at $189 \mathrm{~m}$.u. The NMR spectrum (in $\mathrm{d}_{6}$ DMSO) showed a two-proton singlet at $\delta 7.5$ for the methylene protons adjacent to the benzene ring and an elevenproton multiplet at $\delta \quad 1.2-2.5$. The above data clearly suggest that $\mathrm{N}$-alkylation had taken place followed by hydrolysis yielding the secondary amine (7).

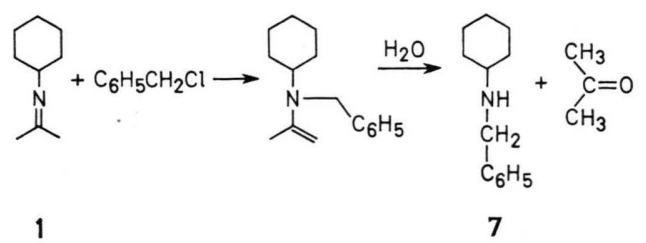

The ketimine was similarly refluxed with four times excess of acrylamide for 26 hours, in a mixture of dry dioxan and dimethylsulphoxide in the presence of a catalytic amount of $p$-toluenesulphonic acid. The product was basified and the corresponding crystalline oxalate m.p. $200-203^{\circ} \mathrm{C}$ (45\% yield) prepared which analysed for $\mathrm{C}_{9} \mathrm{H}_{18} \mathrm{~N}_{2} \mathrm{O}$ 
$(\mathrm{COOH})_{2}$. The mass spectrum showed a molecular ion at $m / e$ 170. Its NMR (in $\mathrm{d}_{6}$ DMSO) exhibited two peaks of one proton each at $\delta 7.0$ and $\delta 7.59$ for the $-\mathrm{NH}_{2}$ of the amide group. There was a twoproton triplet at $\delta 3.1(J=6 \mathrm{cps})$ of the methylene protons adjacent to the nitrogen and a two-proton multiplet at $\delta 2.5$ for the methylene protons geminal to the amide group. Eleven protons of the cyclohexyl moiety resonated in the region between $\delta$ 1.2-2.0. It can therefore be said that in this case also N-alkylation had taken place and subsequent hydrolysis resultet in the formation of the secondary amine (8).

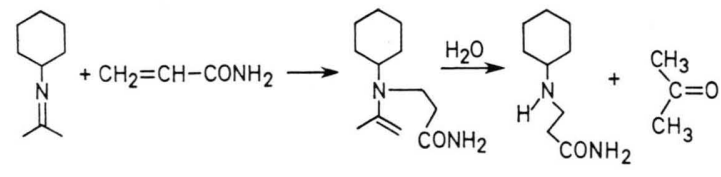

1

8

N-ethylidene cyclohexylamine and acrylonitrile were taken in equimolar quantities and refluxed in dry benzene for two hours. T.l.c. showed one major faster moving spot. The benzene was distilled off and the residue extracted into ether from a basic solution. The ethereal extracts on concentration and addition of oxalic acid afforded a crystalline oxalate m.p. $198-200{ }^{\circ} \mathrm{C}(50 \%$ yield $)$. Micronanalysis suggested that its molecular formula to be $\mathrm{C}_{9} \mathrm{H}_{16} \mathrm{~N}_{2}$. The infrared spectrum of the compound showed a peak at $2250 \mathrm{~cm}^{-1}$ of the carbon-nitrogen triple bond stretching vibration. The NMR (in $d_{6}$ DMSO) spectrum showed a twoproton triplet of the methylene adjacent to the nitrogen at $\delta 3.29(J=6 \mathrm{cps})$ and a two-proton triplet of the methylene adjacent to cyano group at $\delta 2.98(J=6 \mathrm{cps})$. The above data indicate that $\mathrm{N}$-alkylation had followed by hydrolysis yielding the secondary amine $(9)$.

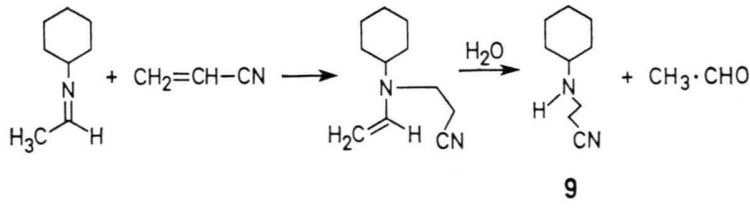

$\mathrm{N}$-ethylidene cyclohexylamine was treated with ethylbromoacetate and the product extracted into benzene from an aqueous ammoniacal solution. Treatment with oxalic acid in ether afforded the crystalline oxalate m.p. $190-193{ }^{\circ} \mathrm{C}(40 \%$ yield, crystallization from methanol) the analysis of which showed the molecular formula of the base to be $\mathrm{C}_{13} \mathrm{H}_{25} \mathrm{O}_{3} \mathrm{~N}$. The mass spectrum exhibited the molecular ion at $243 \mathrm{~m} . \mathrm{u}$. The IR spectrum possessed a peak at $1740 \mathrm{~cm}^{-1}$ and no $\mathrm{N}-\mathrm{H}$ stretching vibrations. The NMR spectrum (in $\mathrm{d}_{6} \mathrm{DMSO}$ ) exhibited a quartet of the methylene protons of the ester group at $\delta 4.2$ and a three-proton singlet of the methoxy group at $\delta 3.89$. The above physical data indicate that one molecule of each had reacted and $\mathrm{N}$-alkylation was followed by addition of a molecule of methanol on the carbon-carbon double bond during the crystallisation of the oxalate salt from methanol, thus yielding the tertiary amine (10).

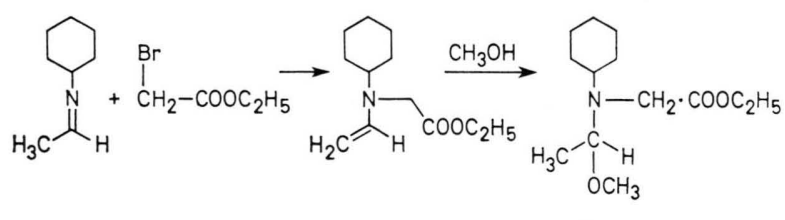

10

The above alkylations of the ketimine and aldimine therefore afforded only $\mathrm{N}$-alkylation products under the conditions examined. Our results are therefore sharply in contrast to those of PFAU and RIBIERE $^{9,10}$ who have reported only C-alkylation products via the enamine tautomers of imines. Indeed it is extremely surprising that no $\mathrm{N}$-alkylated products were obtained by PFAU and RIBIERE in view of the existence of a mobile equilibrium between the imine and enamine forms of ketimines. Moreover this equilibrium is strongly displaced towards the imine form as was demonstrated by Pfau and Ribiere (l.c.) by NMR studies of deuterated isopropylidene-isopropylamine and by AtTA-UR-RAHMAN ${ }^{7}$ on NMR studies of deuterated harmaline.

It is therefore evident that scope of the C-alkylation reactions of ketimines and aldimines via their enamine tautomers is limited. If the imine can be made to exist predominantly in the enamine form, say by $\mathrm{N}$-silylation of the ketimine and aldimine, then one would expect facile C-alkylation to occur; the $\mathrm{N}$-silyl group could subsequently easily be removed. Such a study is currently under progress. The above procedure of hydrolysis of the 
alkylated ketimine or aldimine, however, offers an of secondary amines from the corresponding alternative method for the preparation of a variety primary amines.

1 G. Stork, R. Terrell, and J. Szmuszkovicz, J. Amer. Chem. Soc. 76, 2020 [1954].

2 G. Stork and H. K. Landesman, J. Amer. Chem. Soc. 78, 5128 [1956].

3 J. H. Burckhalter and J. H. Short, J. Org. Chem. 23, 1278 [1958].

4 W. H. Perkin Jr. and R. Robinson, J. Chem. Soc. 115, 933 [1919].

5 R. A. Abramovitch and I. D. Spenser, Adv. Heterocycl. Chem. 3, 191 [1964].

6 Atta-ur-Rahman and Tayyaba Burney, Pak. J. Sci. \& Ind. Res. 15 (1), 9 [1972].

7 Atta-ur-Rahman, J. C. S. Perkin I, 731, 736 [1972].

8 Atta-ur-Rahmann and Fatima Zehra, Pak. J. Sci. \& Ind. Res. $15(4,5), 266$ [1972].
9 M. Pfau and C. Ribiere, Chem. Commun. 1, 66 [1970].

10 M. Pfau and C. Ribiere, Bull. Soc. Chim. France 7, 2584 [1971].

11 F. Bohlmann, D. Habeck, E. Poetsch, and D. Schumann, Chem. Ber. 100, 2742 [1967].

12 S. G. Ayabalyan, Zh. A. Khanamiryan, and A. O. Nshanyan, Arm. Khim. Zh. 21 (5), 422 [1968].

$13 \mathrm{~K}$. N. Campbell, A. H. Sommers, and B. K. Campbell, J. Amer. Chem. Soc. 66, 82 [1944].

14 D. G. Norton, V. E. Hanry, F. C. Davis, L. J. Mitchell, and S. A. Ballard, J. Org. Chem. 19, 1054 [1954]. 